\title{
Conexão Letras 誉息

\section{A IRONIA COMO UM RECURSO SEMÂNTICO-DISCURSIVO CONSTRUÍDO PELA INVERSÃO DAS RELAÇÕES EU-TU-ELE E EU-OUTRO}

THE IRONY AS A SEMANTIC-DISCURSIVE FEATURE BUILT BY INVERSION OF THE

RELATIONS I-YOU AND I-OTHER

Andre Cordeiro dos Santos ${ }^{1}$

Resumo: Este trabalho se detém ao estudo da ironia que se constrói pela inversão das relações eu-tu-ele (BENVENISTE, 1976; 2006), no nível linguístico, e eu-outro (VOLÓCHINOV, 2017 [1929]), no nível do discurso. Para tanto, apesar de sabermos das diferenças entre as duas perspectivas, propomos uma articulação entre os estudos de Benveniste, no que se refere à categoria de pessoa da enunciação, e os estudos do Círculo de Bakhtin, sobre as relações dialógicas que se expressam na relação eu-outro. Como corpus, tomamos enunciados-discursos irônicos nos quais mulheres assumem uma posição de resistência perante discursos machistas, justamente pela inversão das relações acima postas. A partir deste estudo, foi possível perceber que a inversão das relações eu-tu-ele e eu-outro institui o discurso de resistência de mulheres frente aos vários discursos machistas sobre o estupro que as subjugam.

Palavras-chave: A ironia. A relação eu-tu. A relação eu-outro. Discurso de resistência.

Abstract: This paper focused on the study of irony that is constructed by the inversion of the I-you relation (BENVENISTE, 1976; 2006), at the linguistic level, and the I-Other relation (VOLÓCHINOV, 2017 [1929]), at the discursive level. To this end, although we know of the differences between the two perspectives, we proposed an articulation between Benveniste's studies, on the category of person of enunciation, and the studies of the Bakhtin's Circle, on the dialogic relations expressed in the I-Other relation. As a corpus, we take ironic statements-discourses in which women assumed positions of resistance to sexist discourses, precisely by the inversion of the relationships put forward. From this study, it was possible to perceive that the inversion of the I-you-he[she-it] and I-Other relations are responsible for fomenting the discourse of resistance of women against the various sexist discourses about the rape that subjugate them (women).

Keywords: The irony. I-you relation. I-Other relation. Discourse of resistance.

\section{Introdução}

Pensar a linguagem requer que se considere, além das questões puramente linguísticas, as questões sociais que dizem sobre o contexto social e os sujeitos em interação. Essa afirmação se ampara nos estudos do chamado Círculo de Bakhtin², que, mesmo reconhecendo a importância das relações sistêmicas que se estabelecem no nível da língua (BAKHTIN, 2016 [1952/53]), expande essa visão e compreende a enunciação como sendo social

\footnotetext{
${ }^{1}$ Doutor em Linguística pela Universidade Federal de Alagoas. Professor de Língua Inglesa do Instituto Federal de Alagoas - Campus Piranhas. E-mail: andre.cordeiro@ifal.edu.br.

${ }^{2}$ Grupo de estudiosos russos composto por Bakhtin, Volóchinov, Medviédev, entre outros.
} 
(VOLÓCHINOV, 2017 [1929]). Assim, compreender os fenômenos semânticos-discursivos requer a consideração da materialidade linguística do enunciado para adentrar no "universo" do discurso, possibilitando a produção de sentidos de forma mais adequada aos diferentes contextos de interação discursiva.

É importante mencionar a questão acima porque consideramos que a construção de sentido não prescinde à consideração da língua com seus elementos em relação. No entanto, não devemos nos restringir a ela, pois, devido à grande complexidade que perpassa a construção de sentido, é indispensável se pensar a parte irrepetível, social e dialógica da linguagem. Pensando assim, para fins de análise do fenômeno semântico-discursivo da ironia, propomos a articulação entre o entendimento de enunciação de Émile Benveniste e o entendimento de enunciação do Círculo de Bakhtin. Propomos, sobretudo, analisar a ironia como um recurso semântico-discursivo que se institui pela inversão das relações eu-tu-ele, no nível linguístico (BENVENISTE, 1976) e eu-outro, no nível do discurso (VOLÓCHINOV, 2017, [1929]).

A perspectiva enunciativa de Benveniste (1976; 2006) surge a partir do questionamento sobre como se dá a passagem da língua ao discurso ${ }^{3}$, o que o fez tomar o ato individual de apropriação da língua por um falante como objeto de estudo - a enunciação. Apesar de Benveniste trazer a enunciação para os estudos da linguagem, é importante mencionar que ele não rompe com Ferdinand de Saussure, pois se mantém fiel a conceitos deste, ao estudar as relações entre língua e espaço social na materialidade linguística. Dentro do entendimento de enunciação de Benveniste, há a consideração de três categorias, que seriam sempre diferentes, fazendo a enunciação sempre única: a categoria de pessoa, a categoria de lugar e a categoria de tempo. Ou seja, a mudança nessas instâncias do discurso imporia mudança de sentido.

Já a perspectiva do Círculo de Bakhtin, embora faça uso constante dos termos enunciado e enunciação, está mais relacionada à dimensão dialógico-discursiva da linguagem. Os sentidos são sempre únicos porque as situações discursivas implicam relações sócio-dialógicas específicas, interações entre vozes sociais diversas, um contexto social, sujeitos em interação e ideologias. Dentro dessa perspectiva, a enunciação comporta a relação eu-outro (ambos sujeitos sociais e únicos) e esse "outro" é elemento constitutivo do enunciado, pois ele está implicado no que é dito.

\footnotetext{
${ }^{3}$ Discurso em Benveniste diz respeito à atualização da língua que ocorre quando um falante assume o lugar do "eu" (um dos elementos constitutivos da categoria de pessoa) (FLORES et al., 2009, p. 84).
} 
No que se refere à ironia, tomamos a definição de Booth (1983), do seu texto The empire of irony ${ }^{4}$, no qual ele faz uma retomada histórica do fenômeno da ironia. Para o autor, sendo um princípio estético (estilístico) de constituição discursiva, ela cria lugares de resistência e, por conseguinte, pode se mostrar como sendo altamente ideologizado, ao fingir conciliar valores sociais conflituosos, juntando vozes sociais diversas e, assim, permitindo aos sujeitos apropriar-se de vozes outras para ridicularizá-las. Nesse processo de apropriação de vozes de outrem, a partir do que defende o autor, é possível supor que essas vozes que são apropriadas pelos sujeitos, no fenômeno da ironia, serão de outros grupos sociais que, normalmente, opõem-se ideologicamente aos seus próprios, em algum sentido.

Por considerar as noções acima, trazemos à discussão, neste artigo, um tipo específico de ironia, que se mostra como um discurso de resistência da mulher em relação aos discursos machistas, constituindo-se semântico-discursivamente pela mudança nas relações eu-tu-ele, no nível linguístico, e eu-outro, no nível discursivo. Nesses discursos mulheres se apropriam de discursos machistas socialmente correntes que culpabilizam a mulher que é vítima de algum tipo de abuso de natureza sexual e os usam para comentar uma situação vivenciada por um homem, no intuito de contestar esses discursos, em enunciados como "Aposto que se fosse um rapaz sério não estava usando banheiro público $[\ldots]^{5 "}$. Consideramos que esse tipo de ironia se apropria de dizeres de grupos sociais opostos ideologicamente e, nesse processo, acaba por implantar um outro "eu" em relação a um novo "tu", invertendo a relação eu-tu-ele benvenistiana (1976), a fim de contestar esse dizer alheio, instaurando novo sentido na enunciação. Atrelado a isso, no nível discursivo, na relação eu-outro, postulada pelo Círculo de Bakhtin, temos a implantação de um jogo dialógico de atrito entre vozes sociais, na medida em que o sujeito enunciador finge compartilhar da posição ideológica alheia para, assim, contestá-la.

Diante disso, nosso objetivo neste artigo é ver como a mudança da relação eu-tu-ele (no nível da língua) e da relação eu-outro (no nível do discurso) é responsável pela construção de um determinado tipo de ironia e, ao mesmo tempo, pela construção de um discurso de resistência. Para cumprir o objetivo supracitado, selecionamos, como corpus, três enunciados, surgidos a partir de uma publicação anônima - numa página do tipo spotted, que se caracteriza pelo anonimato dos autores das publicações - que circulam na rede social Facebook, nos quais mulheres lançam mão da ironia para mostrar a inconsistência de

\footnotetext{
${ }^{4}$ Em português: "O império da ironia".

${ }^{5}$ Este e outros enunciados do mesmo tipo são analisados na seção Análise das relações eu-tu-ele e eu-outro como instauradoras dos efeitos de sentido em enunciados irônicos deste artigo.
} 
discursos machistas em relação a elas. Esses comentários foram coletados de uma página pública do Facebook nomeada Spotted UFMG - VSF.

Como já indicado acima, apoiamo-nos na articulação entre duas perspectivas enunciativas de linguagem para o estudo desses fenômenos semântico-discursivos: a perspectiva de Benveniste e a perspectiva do Círculo de Bakhtin. Cabe ressaltar que reconhecemos a diferença entre as duas perspectivas enunciativas, no entanto, ela se justifica na medida em que é nosso interesse observar como o tipo de ironia que é nosso objeto de estudo se constitui no nível da língua e no nível do dialógico-discurso.

Cabe ainda mencionar que este artigo surge a partir das discussões que se deram no contexto da disciplina Teorias Semânticas, do Programa de Pós-graduação em Linguística e Literatura, da Universidade Federal de Alagoas.

Dito isso, a seguir, trazemos à discussão a perspectiva enunciativa de Benveniste e a perspectiva enunciativa do Círculo de Bakhtin.

\section{Enunciação em Benveniste e no Círculo de Bakhtin: uma articulação possível?}

A área de estudo que se detém à investigação da construção de sentido na enunciação é marcada por grande diversidade de teorias. Essa diversidade, segundo Flores (2013), em texto introdutório à Semântica da Enunciação, pode ser percebida desde a própria denominação da área de estudo - que pode ser chamada de semântica da enunciação, teoria da enunciação ou linguística da enunciação - até a própria compreensão do seu objeto de estudo, a enunciação. Essa pluralidade de teorias nos estudos da enunciação foi o que levou Flores et al. (2009) à criação de um dicionário de linguística da enunciação, no qual se define as diferentes compreensões das noções relacionadas às teorias da enunciação, sob as óticas dos diferentes estudiosos, nas diferentes perspectivas enunciativas.

Devido à complexidade e à multiplicidade da área, Flores (2013) adverte que objeto de estudo da semântica da enunciação é a enunciação, no entanto, é preciso ter em conta que ela será algo distinto para cada autor dessa área. Desse modo, ainda segundo Flores, quando queremos fazer análise enunciativa, temos que nos vincular a uma teoria para poder fazer semântica enunciativa. Além disso, cabe mencionar o que Flores (2013, p. 96) nos diz sobre o que se entende por análise enunciativa, para o autor, "é uma análise do ponto de vista do sentido - logo, semântica - sobre a língua em sua totalidade”. Para o estudioso, é nesse sentido que se deve entender a expressão semântica enunciativa.

Dito isso, já que propomos a articulação de duas teorias, passamos à discussão das compreensões de enunciação de Benveniste e do Círculo de Bakhtin, que, de acordo com 
Flores et al. (2009), podem ser assim definidas, respectivamente, como: "Colocação da língua em funcionamento por meio de um ato individual de utilização" (FLORES et al., 2009, p. 102) e "Materialização da interação verbal de sujeitos históricos" (FLORES et al., 2009, p. 99).

\subsection{A COMPREENSÃO DE ENUNCIAÇÃO DE BENVENISTE}

As teorias da enunciação começam a ganhar destaque no campo dos estudos da linguagem a partir do que Bárbara Weedwood (2002) chama de guinada pragmática, ou seja, quando as questões além do sistema linguístico começam a ganhar destaque na compreensão dos fenômenos da linguagem. Dentre as perspectivas que surgiram a partir da consideração da dimensão social da linguagem está a linguística da enunciação. O principal representante dessa perspectiva seria Émile Benveniste (FLORES; TEIXEIRA, 2015, p. 29), sendo, em alguns casos, considerado o pai da Linguística da Enunciação.

Segundo Flores e Teixeira (2015, p. 29), Benveniste foi o primeiro linguista, a partir do quadro saussuriano, a desenvolver um modelo de análise da língua especificamente voltado à enunciação. Ao tratar da enunciação, ou seja, a língua em uso, Benveniste vai além dos limites impostos pelo empreendimento de Saussure (1991), no entanto, ele ainda se mantém fiel ao pensamento daquele, pois conserva concepções que lhe são caras, como a de sistema, a de relação e a de signo, mas, ao mesmo tempo, apresenta meios de tratar da enunciação, que implica o homem na língua (FLORES; TEIXEIRA, 2015, p. 30).

Para tanto, Benveniste precisou expandir noções que se faziam presentes no empreendimento de Saussure (1991), como é o caso, por exemplo, do estudo dos sentidos da língua. Essa questão é tratada no texto $A$ semiologia da língua, no qual o autor busca mostrar que "A língua nos fornece o único modelo de um sistema que é semiótico simultaneamente na sua estrutura e no seu funcionamento" (BENVENISTE, 2006, p. 63). Para cumprir seu objetivo, ele, em relação à língua, argumenta que:

\footnotetext{
$1^{\circ}$ ela se manifesta pela enunciação, que contém referência a uma situação dada; falar, é falar-de;

$2^{\circ}$ ela consiste formalmente de unidades distintas, sendo que cada uma é um signo;

$3^{\circ}$ ela é produzida e reconhecida nos mesmos valores de referência por todos os membros de uma comunidade;

$4^{\circ}$ ela é a única atualização da comunicação intersubjetiva. (BENVENISTE, 2006, p. 63).
}

Do ponto de vista do autor, a língua teria uma dupla significância, que se constituiria pela articulação do sentido no plano da estrutura e no plano do funcionamento dessa estrutura, ou seja, o modo semiótico e o modo semântico. O modo semiótico designaria o modo de 
significação que é próprio do signo linguístico e que o constitui como unidade; consiste em identificar unidades, em descrever suas marcas distintivas e em descobrir os critérios cada vez mais sutis em sua distinção. O modo semântico diria respeito à significância que é engendrada pelo uso, na enunciação (BENVENISTE, 2006, p. 65).

Como pode ser visto, ao trazer o funcionamento da língua para o estudo dos sentidos, o autor acaba por extrapolar o quadro do empreendimento saussuriano, pois traz o uso para o rol dos estudos do sentido. E a esse respeito, Flores e Teixeira (2015, p. 31) defendem que é justamente essa extrapolação, resumida nessa oposição entre esses dois níveis de significação, o semiótico e o semântico, que sintetiza a perspectiva de Benveniste.

É importante mencionar que esse entendimento da construção de sentido de Benveniste, bem como todo o conjunto dos seus estudos, surge do questionamento de como se dá a passagem da língua ao discurso. Desse questionamento do autor surge o entendimento da enunciação como sendo um ato individual de apropriação da língua que se dá na intersubjetividade dos sujeitos, sendo o sujeito entendido como um indivíduo subjetivo (BENVENISTE, 1976). Além disso, para Benveniste (1976), a enunciação seria sustentada pelas categorias de pessoa, lugar e tempo, ou seja, na instância de discurso, há sempre um $\boldsymbol{E} \boldsymbol{u}$ falando para um $\boldsymbol{T} \boldsymbol{u}$, sobre um Ele, em um Aqui e um $\boldsymbol{A g o r a . ~}$

A despeito dessas categorias desenvolvidas por Benveniste (1976), Flores e Teixeira (2015, p. 30) argumentam que o que de inovador há é justamente a consideração dos sujeitos e estrutura articulados. Essa articulação se evidencia, sobretudo, por meio da categoria de pessoa da enunciação. Nesse artigo, tendo em vista o nosso objetivo, enfocaremos apenas a categoria de pessoa desenvolvida por Benveniste, sobretudo a relação eu-tu-ele.

Ao se deter à categoria de pessoa, Benveniste (1976, p. 250) defende que ela é constituída por "aquele que fala", "aquele a quem nos dirigimos" e "aquele que está ausente", ou seja, o $\boldsymbol{E} \boldsymbol{u}$, o $\boldsymbol{T} \boldsymbol{u}$ e o $\boldsymbol{E l e}$. Dentre essas três pessoas, o $\boldsymbol{E} \boldsymbol{u}$ e o $\boldsymbol{T} \boldsymbol{u}$ constituiriam pessoas do discurso, pois poderiam assumir o lugar de enunciador, enquanto o Ele seria o tema do discurso, a não-pessoa do discurso, por não assumir o lugar de enunciador. Devido a isso, Benveniste (1976, p. 250) defende que as duas primeiras pessoas ( $\boldsymbol{e u}$ e $\boldsymbol{t u}$ ) não estariam no mesmo plano da terceira (ele), pois “ $\mathrm{O}$ 'eu' que enuncia, o 'tu', ao qual o 'eu' se dirige são cada vez únicos. "Ele", porém, pode ser uma infinidade de sujeitos ou nenhum" (BENVENISTE, 1976, p. 253).

Além disso, no que se refere ao par eu-tu, essa relação pode ser revertida, ou seja, “o que 'eu' define como 'tu' pode inverter-se em 'eu', e 'eu' se torna um 'tu' (BENVENISTE, 1976, p. 253). Para Flores e Teixeira (2015, p. 32), esta categoria de pessoa de Benveniste é 
formulada a partir da consideração da significação singular e irrepetível da língua, cuja interpretação só pode se dar mediante a consideração das instâncias de discurso. No nível semiótico, essa significação estaria ausente. No nível semântico, ela seria definidora do sentido porque ele se constrói "pela referência estabelecida entre ideias expressas sintagmaticamente na frase e a situação de discurso" (FLORES; TEIXEIRA, 2015, p. 32).

Desse modo, a partir da consideração da categoria de pessoa de Benveniste, temos um modelo de análise da enunciação, a partir da relação dos interlocutores, que possibilita a construção de sentidos sempre únicos, tendo em vista que as instâncias são também sempre únicas. Consideramos que observar como a mudança da relação dos interlocutores que compõem a relação entre interlocutores na enunciação irônica é fundamental para a compreensão dos sentidos pretendidos. No entanto, mais que considerar o sujeito que está na língua, por meio da categoria de pessoa, consideramos ser necessário analisar também as relações dialógicas e ideológicas entre o eu e o outro, proposta pelo Círculo de Bakhtin. Passemos a essa discussão.

\subsection{A COMPREENSÃO DE ENUNCIAÇÃO DO CÍRCULO DE BAKHTIN}

Antes de adentrarmos a discussão propriamente dita, convém ressaltar que as reflexões sobre linguagem do Círculo de Bakhtin surgiram no início do século XX e são marcadas por um distanciamento do modelo de análise e estudo linguístico da época, o subjetivismo individualista/idealista e o objetivismo abstrato. Com isso, percebemos que, apesar de Benveniste ser tido por alguns como pai da área de estudo, a centralidade da enunciação como objeto de estudo da linguagem é antecipada em algumas décadas pelo Círculo.

O Círculo de Bakhtin, assim, toma o enunciado como unidade por excelência da interação verbal e o modo de vê-lo “(...) aponta para uma concepção de enunciação ${ }^{6}$ em que a língua é considerada em situações concretas, cujos interlocutores, espaço, tempo e projeto discursivo são fundamentais" (FLORES et al. 2009, p. 99). Desse modo, segundo Flores e Teixeira (2012, p. 45), o Círculo de Bakhtin, por meio de suas ideias, anuncia a fundação da enunciação como centro de referência do sentido dos fenômenos linguísticos, "vendo-a como evento sempre renovado, pelo qual o locutor (e também sujeito) se institui na interação viva com vozes sociais".

Sendo assim, um dos pontos centrais dessas reflexões sobre o enunciado é o entendimento da linguagem humana como algo que vai além de um sistema linguístico, como

\footnotetext{
${ }^{6}$ Para Flores (2009, p. 99), enunciado, enunciação e enunciado concreto são tomados por Bakhtin como sinônimos, pois decorrem da tradução ao português de um único verbete. 
algo que é originado de um diálogo único e singular no qual cooperam diversos fatores para a construção do sentido do enunciado. À vista disso, um enunciado é mais que simples repetição de elementos imanentes de um sistema linguístico, pois, segundo Bakhtin,

O enunciado nunca é apenas um reflexo, uma expressão de algo já existente fora dele, dado e acabado. Ele sempre cria algo que não existia antes dele, absolutamente novo e singular e que, ademais, tem relação com o valor (com a verdade, com a bondade, com a beleza, etc) (BAKHTIN, 2016 [1959/61], p. 95).

Além disso, cada enunciado se constitui como algo não repetível, pois, mesmo a repetição exata de um enunciado (linguisticamente falando), não comportará mais o mesmo significado, não terá mais o mesmo sentido. Essa questão retoma o que Volóchinov (2017 [1929]) chama de tema e significação.

Para Volóchinov (2017 [1929]), o enunciado é composto por duas partes: o tema e a significação. O tema diz respeito a "Uma significação única e determinada, isto é, um sentido único pertencente a qualquer enunciado como uma totalidade”. Já por significação, Volóchinov entende “(...) aqueles aspectos do enunciado que são repetíveis e idênticos a si mesmos em todas as ocorrências" (VOLÓCHINOV, 2017 [1929], p. 227-228, grifos do autor). A enunciação se constitui, nesse modo de pensar, como um tema, quando em situação concreta, que se serve de uma significação (aparato técnico que permite a enunciação). Nas palavras de Volóchinov,

O tema é um complexo sistema dinâmico de signos que tenta se adequar ao momento concreto da formação. O tema é uma reação da consciência em constituição para formação existencial. A significação é um artefato técnico de realização do tema. [...] [No entanto] o tema deve apoiar-se em alguma significação estável, caso contrário ele perderá a sua conexão com aquilo que veio antes e que veio depois, ou seja, perderá totalmente seu sentido (VOLÓCHINOV, 2017 [1929], p. 229, grifos do autor).

É a partir desse modo de pensar que Flores e Teixeira (2012, p. 52-53) afirmam que o método sociológico de ver a língua, proposto por Volóchinov, integra os elementos abstratos da língua à estrutura da enunciação, entendida como um espaço de diálogo entre diversas instâncias de discurso ${ }^{7}$ e acentos apreciativos.

A partir desse excerto supracitado, percebemos também que forma e uso são considerados no tratamento da questão do enunciado, mas, mesmo reconhecendo a importância do aparato técnico da enunciação, “(...) o que importa é o caráter de novidade, o evento, aquilo que pertence à circulação de posições avaliativas de sujeitos do discurso e a permanente renovação de sentidos" (FLORES et al., 2009).

\footnotetext{
${ }^{7} \mathrm{O}$ discurso para o Círculo de Bakhtin é entendido como a linguagem em sua integridade viva e concreta (FLORES et al., 2009, p. 84). 
No modo de ver o enunciado do Círculo, também é fundamental a orientação social para outrem, pois é impossível, nessa perspectiva, interação sem relação eu-outro. Nas palavras de Volóchinov,

\begin{abstract}
A palavra [...] é determinada tanto por aquele de quem ela procede quanto por aquele para quem ela se dirige. Enquanto palavra, ela é justamente o produto das inter-relações do falante com o ouvinte. Toda palavra serve de expressão de um "eu" em relação ao "outro". [...] A palavra é a ponte que liga o eu ao outro (VOLÓCHINOV, 2017 [1929], p. 205, grifos do autor).
\end{abstract}

O enunciado, assim, caracteriza-se como "resultado" de enunciados anteriores, da consideração do outro (sujeito social) da interação, portanto, dialógico, e, por isso, a monologicidade é algo impraticável em se tratando de interação verbal, de enunciados concretos. É nesse sentido que Bakhtin diz que:

\begin{abstract}
Por mais monológico que seja um enunciado (por exemplo, uma obra científica ou filosófica), por mais concentrado que esteja no seu objeto, não pode deixar de ser em certa medida também uma resposta àquilo que já foi dito sobre dado objeto, sobre dada questão, ainda que essa responsividade não tenha adquirido uma nítida expressão externa: ela irá manifestar-se na tonalidade de sentidos, na tonalidade de expressão, na tonalidade de estilo, nos matizes mais sutis da composição (BAKHTIN, 2016 [1952-53], p. 58-59).
\end{abstract}

A respeito disso, podemos afirmar que, sendo o enunciado posto como a unidade por excelência da interação verbal, ele, como podemos ver no excerto supracitado, se pauta, desde o princípio, na possível reação-resposta do outro, como afirma Rodrigues (2001, p 36), buscando sintetizar a orientação social do enunciado na visão bakhtiniana, ao dizer que "todos os aspectos do enunciado se constroem em vista da atitude de resposta do interlocutor".

Nisso está implícito, como defende Volóchinov (2013 [1930]), que o enunciador leva em consideração a situação (tempo, espaço, objeto que trata a enunciação e avaliação dos interlocutores) em que se encontra e na qual se realiza a interação, os ditos anteriores, os ditos que estão por vir e o próprio interlocutor, não sendo possível, assim, separar o enunciado desses elementos, sem prejuízo ao seu entendimento, pois aqueles são peças-chave para este.

Além disso, deve-se ter em conta a orientação social do enunciado, pois este está sempre voltado a um auditório (entendido como a presença dos participantes da situação) ainda que este não seja real (VOLÓCHINOV, 2013 [1930], p. 157). Para Volóchinov, as orientações para o auditório, junto com a situação, constituem o todo da enunciação.

Reforçando o caráter de orientação para outrem dessa visão do Círculo de enunciado, Flores e Teixeira afirmam que é da crítica à corrente de estudos formais, que considera apenas a parte sistêmica da linguagem, que Volóchinov (2017, [1929]), em MFL, 
virtualidade representativa da comunidade na qual está inserido o locutor e propõe, dessa forma, a ideia de interação verbal realizada por meio da enunciação. A unidade fundamental da língua passa a ser o diálogo, entendido [...] como toda comunicação verbal (FLORES e TEIXEIRA, 2012, p. 51).

Os enunciados se caracterizam como as formas pelas quais a língua ganha vida e se concretiza na comunicação real, permitindo a existência dos discursos dos falantes. Nesse processo, a subjetividade dos interlocutores é fator essencial para a efetivação desses enunciados, pois eles só podem se efetivar na intersubjetividade desses falantes.

Como é a forma da manifestação da interação social/discursiva, o enunciado também se caracteriza pela sua natureza dialógica. Este surge a partir da interação discursiva que se torna concreta através dos falantes a fim de interferir em seu meio, ou esferas das quais faz parte. No entanto, um enunciado nunca será o primeiro nem será o último a ser criado, posto que está em uma cadeia de enunciados que mantêm um elo entre si, evidenciando enunciados que o antecederam e apontando para outros que o sucederão. Assim, implícita ou explicitamente, a interação também pressupõe outros discursos, anteriores ou não. Diante disso, podemos dizer que a concepção de enunciado posta é fundamentalmente social.

\subsection{A ARTICULAÇÃO DAS TEORIAS}

Como pudemos perceber, as duas compreensões de enunciação postas acima são diferentes, pois uma está mais voltada à dimensão linguística e a outra à dimensão discursiva. No entanto, consideramos a articulação dessas teorias pois os estudos dos membros do Círculo de Bakhtin não negam a parte imanente da linguagem, apesar de criticarem a perspectiva objetivista abstrata que foca unicamente no sistema de signos linguísticos (VOLÓCHINOV, 2017 [1929]). Diante disso, é possível articular noções dessas duas compreensões de enunciação para o estudo do fenômeno semântico-discursivo da ironia, por meio da transposição da categoria de pessoa de Benveniste, típica da materialidade linguística, para o nível dialógico-discursivo.

Sendo assim, reconhecendo que Benveniste propôs um estudo da enunciação como sendo um ato individual de apropriação da língua, no qual o sujeito se mostra na estrutura linguística, e sabendo que o Círculo de Bakhtin vai além do sistema, alcançando o nível discursivo da linguagem, é que propomos analisar o fenômeno semântico-discursivo da ironia, atentando à relação eu-tu-ele proposta por Benveniste e, a partir disso, em um movimento de expansão desse entendimento, à relação eu-outro, proposta pelo Círculo de Bakhtin. Este artigo faz, assim, uma transposição de reflexões do nível enunciativo-linguístico para o nível dialógico-discursivo, visando ao estudo da ironia. 
Estudos que se baseiam na articulação dessas teorias, como propomos neste artigo, vêm sendo realizados, por exemplo, por pesquisadores como Amorim (2001; 2016). Em seus estudos, por meio da articulação da categoria de pessoa de Benveniste com a teoria dialógica de linguagem, Amorim $(2001 ; 2016)$ discute o lugar do sujeito de pesquisa nas ciências humanas, afirmando que o lugar típico do sujeito é o do ele na categoria de pessoa, o que implica o silenciamento desse sujeito de pesquisa na dimensão dialógico-discursiva. A partir disso, ainda na articulação das teorias, a autora propõe que é preciso uma mudança do lugar de sujeito para o $t u$, sujeito que assume lugar de fala, o que, na dimensão dialógica-discursiva, pressupõe considerar as vozes constitutivas do sujeito e do próprio sujeito.

Com base nessa articulação-transposição, passamos à análise proposta, que será acompanhada de considerações sobre a ironia e os mitos-discursos machista em relação ao estupro da mulher.

\section{Análise das relações eu-tu-ele e eu-outro como instauradoras dos efeitos de sentido em enunciados irônicos}

Como já mencionado anteriormente, neste artigo, partimos do entendimento da ironia como um princípio estilístico-discursivo, que cria lugares de resistência, ao fingir conciliar valores sociais conflituosos, juntando vozes sociais diversas e, assim, permitindo aos sujeitos apropriar-se de vozes outras para ridicularizá-las (BOOTH, 1983). Em face dessa noção, tomamos enunciados de mulheres, presentes no Facebook, nos quais elas buscam contestar discursos machistas normalmente usados contra mulheres.

Esses comentários foram coletados de uma página pública do Facebook nomeada de Spotted UFMG - VSF ${ }^{8}$. As páginas do tipo spotted são caracterizadas pelo anonimato de suas publicações. Os comentários, no entanto, não são anônimos e, apesar de ser uma página de acesso público, optamos por preservar a identidade das leitoras que postaram comentários-respostas à postagem. Como a análise se dará a partir de enunciados-comentários surgidos como resposta à uma postagem, apresentamos a postagem que os gerou a seguir:

Figura 1: publicação do Facebook.

\footnotetext{
${ }^{8}$ Essa página, segundo descrição do criador, surgiu devido à constatação de que não só de amores viveria a Universidade Federal de Minas Gerais, mas, também, de discórdias. Por isso, essa página se caracterizaria como um espaço no qual as pessoas da própria universidade poderiam mandar um "VSF" (sigla para "vai se foder") para pessoas e situações da mesma universidade, de forma anônima.
} 


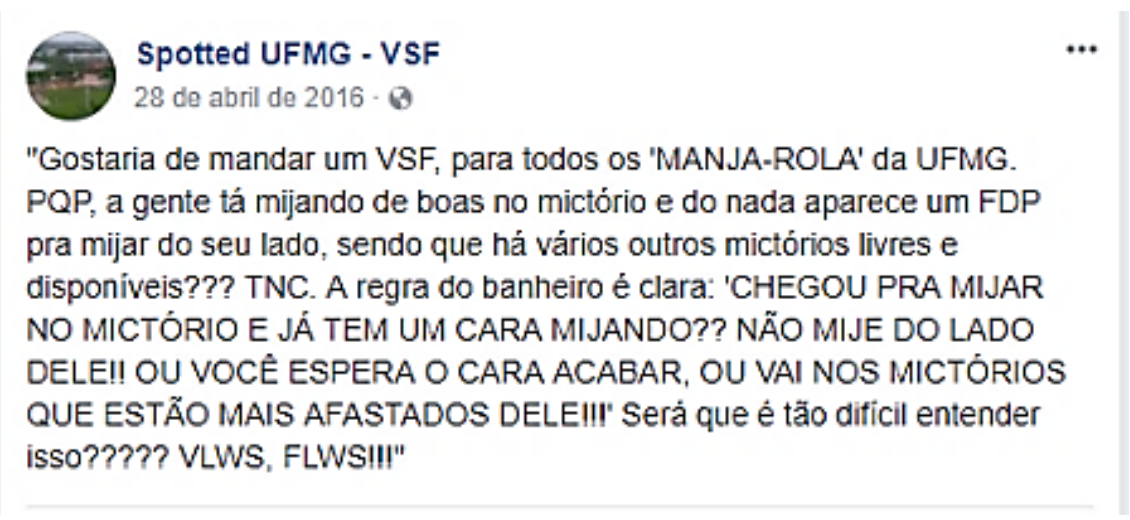

Fonte: Facebook.

$\mathrm{Na}$ postagem acima, podemos perceber que o autor (um homem, pelos indícios textuais) está revoltado com o comportamento de outros homens no banheiro da Universidade Federal de Minas Gerais. Segundo ele, os demais usuários do banheiro estariam descumprindo as regras de conduta e, com isso, olhando para o seu pênis. Essa postagem demonstra o incômodo do autor frente à situação e é ele que serve de enunciado-gerador para os comentários que serão aqui analisados.

Os comentários que surgiram a partir dessa postagem foram muitos e bem variados, no entanto, optamos por analisar apenas três deles, devido à limitação de espaço que este artigo impõe, no quais a ironia se faz presente e, também, nos quais discursos machistas relacionados ao estupro contra a mulher se fazem presentes, res-significados pela mudança das relações eu-tu-ele e eu-outro.

Vejamos a seguir o comentário da leitora 1:

Figura 2: comentário 1.

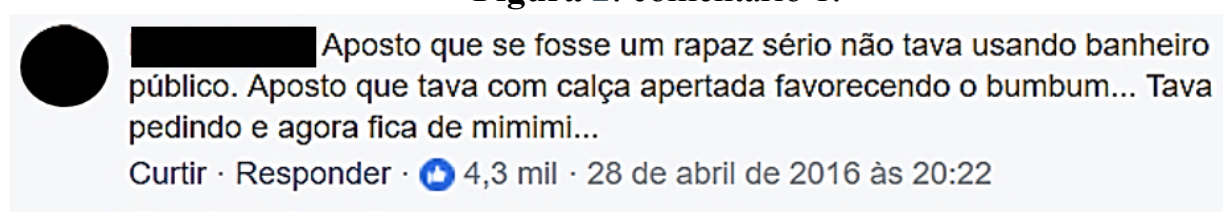

Fonte: Facebook.

O comentário da leitora 1 vem questionar a reputação do autor da postagem, dizendo acreditar que ele deveria estar com roupa vulgar, por isso, estaria pedindo para ser "assediado" e a postagem, diante de tudo, não passaria de uma reclamação infundada. Ao fazer isso, a leitora 1 se apropria do discurso machista de que a mulher que sofre violência sexual se expõe a situações de risco, usa roupas vulgares e que o assédio deveria ser tomado como elogio.

Ao se apropriar de um discurso que, geralmente, é proferido por homens em relação a mulheres, a leitora 1 inverte a relação eu-tu-ele prototípica do enunciado e acaba por tomar o 102 - Conexão Letras, Porto Alegre, v. 16, n. 25, p. 91-106, jan-jun. 2021. 
lugar do eu e colocar o homem no lugar do tu-ele - ao mesmo tempo que ele é o tu para quem enunciado se dirige, também o é o ele, objeto da enunciação - no nível linguístico, partindo da categoria de pessoa de Benveniste (1976). Como esse novo eu, mulher, e esse novo tu-ele, homem, não são as pessoas do discurso esperadas, o sentido acaba sendo mudado, instaurando a ironia na enunciação, visando a contestação do discurso machista.

Para melhor entendermos essa contestação, precisamos levar essa relação ao nível dialógico-discursivo do enunciado, e, assim, percebemos que temos a instauração de uma nova relação eu-outro (VOLÓCHINOV, 2017 [1929]), pois o eu, mulher que é normalmente vítima desses discursos-mitos, passa da condição de vítima para a condição de acusadora do outro (homem, que normalmente é o acusador), ao fingir se apropriar de um posicionamento alheio. Por meio dessa apropriação fingida, a leitora instaura uma zona dialógica de atrito entre vozes no enunciado, caracterizada pela inversão da relação eu-outro, mostrando o quão infundados são os discursos machistas apropriados.

No comentário da leitora 2, temos a apropriação de mais um discurso-mito dentro dos que são apontados por Sousa (2017). Vejamos:

Figura 3: comentário 2.

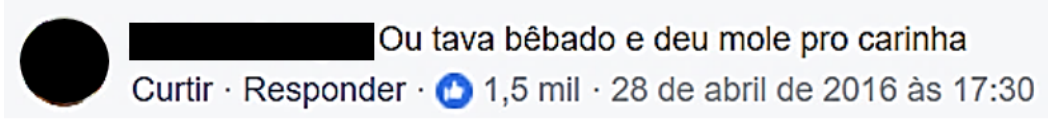

Fonte: Facebook.

O comentário da leitora 2 vem dizer que, para ter passado pela situação relatada na postagem, o homem deveria estar ou bêbado ou insinuando-se para os demais homens no banheiro. $\mathrm{O}$ comentário da leitora 2 incorpora um mito relacionado à cultura do estupro e, nesse processo de apropriação, a relação eu-tu-ele é invertida: o eu dessa enunciação, que normalmente é um homem, passa a ser uma mulher e o tu-ele, que normalmente é uma mulher, passa a ser um homem. Essa inversão instaura novos sentidos e tem consequências no nível discursivo. No nível discursivo, a relação eu-outro é mudada, na medida em que ao se apropriar de um dizer machista, do qual a mulher geralmente é vítima, o sujeito enunciador (leitora 2), acaba por instaurar, na enunciação, um atrito entre lugares sociais ocupados e vozes outras, o que caracteriza a ironia e, também, contesta o discurso-mito apropriado.

Por fim, temos o comentário da leitora 3, no qual há a apropriação do discurso que atribui o assédio a um suposto instinto masculino e, por isso, também se apropria do discurso de que seria mais fácil evitar se expor a situações nas quais esse instinto pudesse aflorar. Vejamos:

Figura 4: comentário 3. 
É assim mesmo, os homens possuem o instinto sexual mais aguçado, faz parte da Natureza masculina é dificil pra eles se controlarem, é mais fácil você não ficar atiçando

Curtir · Responder · $762 \cdot 1$ de maio de 2016 às 11:49 · Editado

Fonte: Facebook.

No comentário acima, a leitora 3 diz que é normal a atitude relatada na postagem, devido ao instinto que seria inerente ao homem e, diante disso, o mais fácil seria tentar se resguardar de situações que ofereceriam risco, como a situação relatada na postagem. Nessa enunciação, a leitora 3, mulher, e, por isso, normalmente ocupante da posição tu-ele, acaba por se mostrar na enunciação como o eu e o homem, autor da postagem, normalmente, por ser um discurso machista, ocupante da posição eu, acaba ocupando a posição tu-ele. Essa inversão das posições eu-tu-ele linguística, muda o sentido de uma enunciação-discurso-mito socialmente corrente. Essa mudança na categoria de pessoa, no nível linguístico, transpõe-se ao nível dialógico-discursivo, pondo vozes em confronto dialógico, levando à mudança da relação eu-outro. Ou seja, a leitora 3, mulher, acaba por trazer ao seu discurso uma voz alheia machista para se posicionar em relação ao outro do seu enunciado. Nessa inversão, numa relação dialógica de tensão entre dizeres, acaba por evidenciar o enunciado como uma zona de conflito, visando contestar, mostrando inconsistência, os discursos machistas.

Diante dessa análise, podemos perceber que, no tipo de ironia analisado, temos a inversão das relações eu-tu-ele, no nível linguístico (BENVENISTE, 1976), e eu-outro, no nível dialógico-discursivo (VOLÓCHINOV, 2017 [1929]), o que acaba caracterizando a ironia nos comentários das leitoras das postagens e, assim, criando lugares de resistência da mulher em relação aos discursos machistas que culpabilizam a mulher pelo assédio sexual sofrido. Sendo assim, consideramos que a consideração dessas relações e de suas possíveis mudanças é indispensável para o entendimento do sentido que se instauram na enunciação por meio desse tipo de ironia.

\section{Considerações finais}

Este artigo teve como objetivo analisar a inversão das relações eu-tu-ele e eu-outro em enunciados irônicos, partindo da hipótese de que essa mudança seria responsável pela instauração do sentido semântico-discursivo do enunciado, caracterizando-o como um discurso de resistência da mulher em relação aos discursos machistas em relação ao estupro. Para tanto, tentamos articular as noções de enunciação de Benveniste e do Círculo de Bakhtin, sobretudo, no que se refere à categoria benvenistiana de pessoa e às relações dialógicas do 
Círculo. Usamos como corpus para análise, enunciados de mulheres publicados na forma de comentários em rede social.

A partir da análise feita foi possível perceber que, nos comentários das mulheres-leitoras, há a apropriação de discursos machistas sobre o estupro da mulher e, a partir de trocas na relação eu-tu-ele, vozes são postas em conflito, caracterizando a ironia como um ato estilístico-discursivo. Ou seja, a mulher que, normalmente é a vítima - o tu-eledo discurso-mito machista, passa a ocupar a posição do eu, instaurando novos sentidos semânticos; no nível discursivo, a relação eu-outro também sofre alteração, por meio da apropriação polemizada de vozes alheias, assim, ao se apropriar de um discurso do qual ela geralmente é vítima, a mulher instaura uma zona de tensão na enunciação e, desse jogo de valores em tensão, sobressai-se um sentido discursivo irônico, que visa a contestar dizeres outros machistas apropriados.

Outrossim, também foi possível perceber que o entendimento de fenômenos semântico-discursivos requer a consideração da enunciação tanto em suas dimensões linguísticas quanto em suas dimensões sociais. Consideramos, assim, que a articulação proposta neste artigo entre a teoria da enunciação de Benveniste e a teoria enunciativa-discursiva do Círculo de Bakhtin possibilitou olhar o linguístico em sua inter-relação com o dialógico-discursivo na constituição, por meio da ironia, dos discursos de resistências das mulheres em relação aos discursos machistas. Diante disso, é possível ratificar o que defende Booth (1983) sobre a ironia, ou seja, ela acaba por criar lugares de resistência para o oprimido em relação ao opressor.

\section{Referências}

AMORIM, Marilia. O pesquisador e seu Outro. Bakhtin nas Ciências Humanas. 1. ed. São Paulo: Musa, 2001.

AMORIM, Marilia. As ciências humanas e sua especificidade discursiva. In: RODRIGUES, R.H.; ACOSTA-PEREIRA, R.. (Org.). Estudos dialógicos da linguagem e pesquisas em Linguística Aplicada. 1ed.São Carlos: Pedro \& João, 2016, v. , p. 17-46.

BAKHTIN, Mikhail. Os gêneros do discurso. Os gêneros do discurso. Organização, tradução, posfácio e notas de Paulo Bezerra; notas da edição russa de Serguei Botcharov. São Paulo: Editora 34, 2016 [1952/53].

BAKHTIN, Mikhail. O texto na linguística, na filologia e em outras ciências. . Os gêneros do discurso. Organização, tradução, posfácio e notas de Paulo Bezerra; notas da edição russa de Serguei Botcharov. São Paulo: Editora 34, 2016 [1959/60].

BENVENISTE, E. Problemas de Linguística Geral I. Tradução de Maria da Glória Novak e Luiza Neri. São Paulo:. Editora da Universidade de São Paulo, 1976.

BENVENISTE, E. Problemas de Linguística Geral II. Tradução de Eduardo Guimarães et al. Campinas: Pontes editores, 2006. 
BOOTH, Wayne. The Empire of Irony. The Georgia Review, v 37, p. 719-737, 1983.

FLORES, V. et al. Dicionário de Linguística da Enunciação. São Paulo: Contexto, 2009.

FLORES, V. Semântica da Enunciação. In: FERRAREZI JUNIOR; BASSO (Orgs.). Semântica, Semânticas: uma introdução. São Paulo: Contexto, 2013.

FLORES, V.; TEIXEIRA, M. Introdução à Linguística da Enunciação. 2. Ed.. São Paulo: Contexto, 2015.

RODRIGUES, R. H. A constituição e o funcionamento do gênero jornalístico artigo: cronotopo e dialogismo. 2001. 356 f. Tese (Programa de estudos pós-graduados em linguística aplicada e estudos da linguagem) Universidade Católica de São Paulo. São Paulo.

SAUSSURE, Ferdinand de. Curso de linguística geral. São Paulo: Cultrix/USP, 1991.

WEEDWOOD, Barbara. História concisa da linguística. Tradução de Marcos Bagno. São Paulo: Parábola Editorial, 2002.

VOLÓCHINOV, Valentin. Marxismo e Filosofia da Linguagem: problemas fundamentais do método sociológico na ciência da linguagem. Tradução, notas e glossário de Sheila Grillo e Ekaterine Vólkova Américo. São Paulo: Editora 34, 2017 [1929].

VOLÓCHINOV, Valentin. A construção da enunciação. In: VOLOCHINOV, V. A construção da enunciação e outros ensaios. Tradução de João Wanderley Geraldi. São Carlos: Pedro \& João editores, 2013 [1930].

Recebido em: 15/12/2020; Aceito em: 01/05/2021. 